\title{
midiätica@ę)
}

\section{Novas articulações no mercado de música digital a partir da cultura do streaming}

\author{
New articulations in the digital music market from the streaming culture
}

Flávio Marcílio Maia e SILVA JÚNIOR ${ }^{1}$

\begin{abstract}
Resumo
A circulação da música digital nas plataformas de streaming é considerada a principal forma de fruição musical na atualidade pela fácil usabilidade e acesso por meio da internet em dispositivos móveis. Constituído a partir das transformações causadas pela digitalização de processos tecnológicos, o streaming tem modificado o mercado musical trazendo novas relações entre gravadoras, plataformas digitais, artistas e consumidores. Neste artigo serão analisadas duas delas: a atuação do Spotify como uma gravadora e a inserção das empresas agregadoras como mediadoras de artistas e dos serviços de streaming, com o objetivo de apresentar novas possibilidades da produção de música no meio digital.
\end{abstract}

Palavras-chave: Streaming. Agregadoras. Internet. Música digital. Spotify.

\begin{abstract}
The digital music circulation on streaming platforms is considered the main form of music enjoyment today due to its easy usability and internet access on mobile devices. Constituted from the transformations caused by the digitization of technological processes, streaming has changed the music market bringing new relationships between record companies, digital platforms, artists and consumers. In this article will be analyzed two of them: Spotify's performance as a record company and the insertion of the aggregating companies as mediators of artists and streaming services, with the objective of presenting new possibilities of music production in the digital environment.
\end{abstract}

Keywords: Streaming. Aggregators. Internet. Digital music. Spotify.

\section{Introdução}

Com a digitalização da música, ou mais precisamente com a transformação da música em dados e a ascensão da produção musical amadora distribuída pela internet, criaram-se perspectivas para a indústria fonográfica. A formação do mercado de música digital durante os últimos anos pode ser categorizada entre os downloads (fonogramas digitais e compra de arquivos musicais para aparelhos celulares) e o streaming. Hoje com

\footnotetext{
1 Mestre em Comunicação pela Universidade Federal de Sergipe, (UFS). Professor Substituto na Universidade Federal de Alagoas (Ufal). 


\section{midiâtica(e)}

a rede mundial de computadores mais rápida, o streaming de música se espalha pela rede e destaca-se como o modelo do futuro da música.

A inserção do streaming na indústria fonográfica também trouxe novas formas de se fazer música no meio digital e novos atores para a cadeia produtiva de música. Tanto a produção quanto a distribuição e o consumo realizados no meio digital fogem da lógica estabelecida pelas grandes gravadoras ao serem executadas de maneira autônoma ou "gratuita", e podem se relacionar diretamente com os serviços de streaming. Estes serviços possibilitaram novas articulações que não envolvem apenas música. Empresas de telefonia e da área da tecnologia, segmentos do comércio como os fast-foods e redes sociais passam a se relacionar com o streaming de música ao perceberem a forma de consumo como uma tendência.

Dentre essas articulações, duas serão analisadas neste trabalho com o objetivo de apresentar novas possibilidades de circulação musical no meio digital: uma relacionada à produção de música e a outra à distribuição, ambas tendo como elemento central o streaming. A primeira refere-se a dois projetos do Spotify: o Spotify Sessions e o Spotify Singles, baseados em gravações próprias e na formação de novos produtos de cantores diversos. A segunda é sobre a inserção das empresas agregadoras na cadeia produtiva de música, as quais funcionam essencialmente como fornecedoras de músicas de artistas não vinculados às majors. Os artistas que mais se utilizam das agregadoras são os de nicho, chamados também de independentes ou autônomos.

\section{A cultura do streaming}

$\mathrm{O}$ processo de digitalização, iniciado em meados do século $\mathrm{XX}$, foi crucial para a consolidação do streaming hoje. Santos (2008) explica esse processo como um elemento fundamental para o novo paradigma nas indústrias de comunicação e em especial nas telecomunicações. As transformações tecnológicas que demarcaram o novo século levaram à digitalização das indústrias culturais que, juntamente da internet, proporcionaram a uma nova forma de consumo: por streaming. Não só música, mas produções audiovisuais e também os jogos eletrônicos têm adotado a modalidade de consumo online como a tendência para o futuro, causando algumas transformações: 


\section{midiâtica(e)}

vez que estão todos digitalizados, não se faz necessário desenvolver uma estrutura física para abrigá-los; apenas se faz necessário ampliar as possibilidades técnicas de distribuição dos conteúdos), (b) a ampliação a baixo custo do mercado, permitindo um aumento significativo da produção de bens, que tendem a se especializar em mercados de pequena e média extensão (nichos) e (c) o aumento da oferta de bens propicia a todo produtor encontrar seu consumidor, que por seu turno pode realizar escolhas racionais sobre o que deseja, uma vez que dispõe de dispositivos de busca que lhes permitiria acessar toda informação necessária sobre o produto desejado. (DE MARCHI, 2018, p.218).

No Brasil, os serviços de streaming de música aparecem no início dos anos 2010 e hoje as principais empresas do segmento são o Spotify, a Apple Music e a Deezer. Em 2015, a Federação Internacional da Indústria Fonográfica (IFPI) considerou o país como um mercado de alto desempenho, o que proporcionou a entrada de mais serviços no mercado de música brasileiro. No mesmo ano, a Pró-Música Brasil divulgou que as duas modalidades de streaming (assinatura ou publicidade) representaram respectivamente $35,5 \%$ e $30,1 \%$ do total do faturamento com música digital no Brasil.

Dos formatos digitais, o streaming remunerado por assinaturas mensais foi a modalidade que mais influenciou no desempenho do mercado, crescendo, no primeiro semestre de 2016, 121\% em comparação com o verificado no mesmo período do ano anterior. Os dados divulgados pela Pró-Música Brasil e IFPI indicam um novo momento para a indústria fonográfica brasileira que se reorganiza após um período de declínio com a baixa venda de CD's e com a internet oferecendo novas oportunidades para consumir e fazer música de maneira gratuita. De acordo com o Global Music Report 2018, o Brasil voltou a ter um crescimento expressivo no ano de 2017 no consumo de música digital: as receitas geradas pelos vários modelos de negócio do setor de música gravada cresceram, em 2017, 8,1\% na comparação com 2016, tendo o faturamento global do setor atingido o montante de US\$ 17,3 bilhões.

Os serviços de streaming se apresentam como a novidade/salvação do mercado de música que podem ser definidas como "portais de consumo, promoção e circulação de conteúdos sonoros, operando também como mídias sociais, ou de modo articulado a estas, constituindo espaços híbridos de comunicação social e consumo cultural que escapam às tentativas de classificação generalizantes" (KISCHINHEVSKY, VICENTE e DE MARCHI, 2015, p.2). O streaming vem proporcionando mudanças também no modo de distribuição musical, que tem sido mais disseminada por meio de músicas avulsas, os 


\section{midiâticale}

singles, ou então no lançamento de álbuns EP'S, com poucas músicas. Esse método, cada vez mais frequente entre os artistas reflete ao novo momento da música: a produção de poucas músicas com um alcance maior ao lado de outras produções de outros artistas. Por estarem presentes na forma de plataformas digitais, Vicente, Kischinhevsky e De Marchi (2016, p.2) consideram estes serviços como uma rádio social pois

reivindicam para si um papel central nas indústrias midiáticas na presente década, apresentando-se como redes sociais on-line e como espaços para negociação de identidades, apostando na comodidade dos consumidores e capitalizando as campanhas de criminalização do compartilhamento de fonogramas protegidos por direitos autorais (Ibdem).

O Youtube, apesar de não ser um serviço exclusivo de streaming musical, também tem se destacado como uma plataforma digital de música. Jimmy Iovine, executivo da Apple Music, afirmou que o YouTube é responsável por $40 \%$ da audição de música em geral concentrando o maior acervo de música digital por demanda do mundo (CRUZ, 2016). Observando esse crescimento, a plataforma de vídeos lançou em setembro de 2018 o Youtube Music, um serviço de streaming que traz como diferencial o catálogo de clipes e músicas que são encontradas apenas no canal de vídeos do Google.

A presença dos serviços de streaming de música se fortalece por meio de alternativas que atraem mais o consumidor: seja proporcionando gravações exclusivas em estúdios próprios, diversificando as formas de pagamento ou ampliando o acervo com artistas locais que se inserem nesses serviços por meio das empresas conhecidas como agregadoras, intermediadoras desse novo processo em destaque no mercado da música.

\section{Novos produtos, mesma fórmula}

O Spotify é considerado um dos serviços de streaming mais populares do mundo e do Brasil. Criado em 2006, a companhia sueca conseguiu 113 milhões de assinantes de assinantes em outubro de 2019. Pagando cerca de $80 \%$ de sua receita a gravadoras e artistas, os diferenciais desse serviço são a possibilidade de ouvir as músicas sem ser assinante, mas com a presença de publicidade, e as diversas possibilidades de assinatura: premium, estudante e família. Há também a flexibilidade de consumo musical por diferentes dispositivos, como Chromecast, possibilitando o consumo em televisões inteligentes (Smart TVs), ou pelo próprio smartphone, que por meio de aplicativos pode 


\section{midiâticale}

ser consumido em automóveis. A relação da plataforma com as grandes gravadoras tem sido controversa. Apesar de serem as principais fornecedoras de música para o serviço, o mesmo já cogitou em pensar um sistema de licenciamento direto para músicos e bandas independentes, reduzindo os custos com direitos autorais ao efetuar o pagamento das execuções dos usuários diretamente aos artistas, que não mais precisariam de associações, agências ou selos para essas tarefas. Seguindo essa ideia, o Spotify tem trabalhado com produções próprias, algumas antes de cogitarem esse acordo, como veremos a seguir.

Performances exclusivas e intimistas caracterizam o projeto Spotify Sessions, do serviço do Spotify. Executando todo o processo de gravação e mixagem, a empresa também lança e promove o conteúdo gravado em forma de EP. As gravações são feitas nos escritórios do Spotify espalhados pelo mundo ou em lugares selecionados. As performances dos artistas geralmente são semiacústicas e contam com uma entrevista realizada pelo setor editorial da empresa. Há também toda uma equipe comercial que grava pequenos spots e tiram fotos, para a posterior divulgação dentro do serviço. A plateia é constituída por pessoas selecionados, a maioria da mídia. Geralmente o processo é muito rápido e simples: o artista faz uma rápida passagem de som e são gravadas de três a quatro músicas, tudo sob responsabilidade de algum funcionário do Spotify. A empresa oferece a gravação, mixagem e masterização da sessão; as músicas gravadas ficam a cargo do artista e da gravadora. Custos adicionais, como viagem, maquiagem e instrumentos, ficam por conta do artista.

No Brasil, a primeira edição do Spotify Sessions aconteceu em 2014 com a banda Jota Quest em um estúdio em Belo Horizonte e a segunda edição foi gravada com a banda Scalene no Audio Arena em São Paulo em 2015. O projeto, realizado em várias partes do mundo, é uma maneira de promover o serviço e alcançar mais público, mesclando as gravações com artistas já consolidados no mercado e artistas que estão ganhando visibilidade. O Spotify Sessions é um produto do Spotify que, assim, acaba realizando atividades próprias de uma gravadora no novo cenário do mercado da música. O projeto tem 293 gravações no catálogo e continua acontecendo nos Estados Unidos. Não há previsão de continuidade no Brasil.

O Spotify Sessions apresenta o mesmo conceito do MTV Unplugged, famosa série de gravações realizadas pela MTV, exibida nos EUA pela primeira vez em 1989 que chegou ao Brasil em 1990 com o nome Acústico MTV. O programa (televisivo baseado 


\section{midiâticale}

em gravações acústicas) fez tanto sucesso que se tornou um selo musical, garantindo muitos lucros para a indústria fonográfica. Bandas nacionais como Titãs e Kid Abelha venderam respectivamente 1,7 milhões e dois milhões de cópias de CDs no Brasil. Cerca de trinta bandas brasileiras gravaram com o selo, ganhando discos de platina e de ouro. Com o fim da MTV Brasil em 2013, a série de gravações também deixou de ser executada sendo a última gravação feita em 2012 com o cantor Arnaldo Antunes e voltou a ser gravada em maio de 2019 com o cantor Tiago Iorc. Nos Estados Unidos, o MTV Unplugged terminou em 2009 e em 2017 voltou a ser produzido, apresentando novidades. O cantor canadense Shawn Mendes marcou o retorno das gravações que foram feitas em $360^{\circ}$, ou seja, o vídeo pode ser movimentado e assistido de ângulos diferentes.

É possível estabelecer um quadro comparativo da versão antiga do Acústico MTV com as sessões acústicas gravadas pelo Spotify no qual são perceptíveis características bem distintas entre os produtos baseados num mesmo estilo de produção. Com duas gravações brasileiras, o Spotify Sessions representa uma tentativa de inovar no meio musical a partir do streaming.

Quadro 1: Comparativo com informações do Acústico MTV e do Spotify Sessions

\begin{tabular}{|c|c|c|}
\hline & $A C U ́ S T I C O M T V$ & SPOTIFY SESSIONS \\
\hline DEFINIÇÃO & $\begin{array}{l}\text { Gravações acústicas exibidas na } \\
\text { MTV, que se tornam também } \\
\text { produtos vendidos pelo selo } \\
\text { Acústico MTV. Popular nos anos } \\
1990 \text { e } 2000 \text {. }\end{array}$ & $\begin{array}{l}\text { Sessões acústicas gravadas por } \\
\text { uma equipe especializada do } \\
\text { Spotify. Além de músicas, a } \\
\text { gravação conta com } \\
\text { entrevistas. }\end{array}$ \\
\hline VENDAS & $\begin{array}{l}\text { Contabilizada pelas vendas dos } \\
\text { produtos. }\end{array}$ & Medida por streams. \\
\hline ACESSO & $\begin{array}{l}\text { Pela televisão e pela compra dos } \\
\text { produtos físicos comercializados. }\end{array}$ & $\begin{array}{l}\text { Pelo serviço de streaming em } \\
\text { computadores, dispositivos } \\
\text { móveis e outros suportes } \\
\text { conectados à internet. }\end{array}$ \\
\hline $\begin{array}{l}\text { CONSUMO } \\
\text { MUSICAL }\end{array}$ & $\begin{array}{l}\text { Pela televisão ou pela reprodução } \\
\text { dos produtos gravados em suportes } \\
\text { especializados. }\end{array}$ & Pelo serviço de streaming. \\
\hline MÍDIAS & $\begin{array}{l}\text { Produtos físicos como CD's e } \\
\text { DVD's e plataformas digitais de } \\
\text { música. }\end{array}$ & $\begin{array}{l}\text { Produto exclusivo do Spotify, } \\
\text { existente apenas no modo } \\
\text { digital. }\end{array}$ \\
\hline PIRATARIA & $\begin{array}{l}\text { Durante os anos } 2000 \text { a cópia de } \\
\text { produtos piratas era muito } \\
\text { frequente, inclusive os lançados } \\
\text { pelo Acústico MTV. }\end{array}$ & $\begin{array}{l}\text { Não há indícios de pirataria no } \\
\text { produto do Spotify, }\end{array}$ \\
\hline
\end{tabular}




\section{midiática@}

Fonte: elaboração própria.

As séries de gravações da MTV podem ser encontradas no Spotify e em outros serviços de streaming como expansão do seu produto no meio digital. Já o Spotify faz o contrário: as gravações tornam-se exclusivas da plataforma. Outra questão é que o sucesso do Acústico MTVIMTV Unplugged estava associado ao consumo musical pela televisão. Com a baixa popularidade da emissora (ao menos no Brasil), o projeto não tem a mesma visibilidade, só quando consumido por streaming no Youtube ou nos serviços de música. Porém, ao entrar no meio digital, a MTV disputa audiência com outros produtos, neste caso, as gravações produzidas pelo Spotify.

Outra produção do Spotify é o Spotify Singles. Lançado em 2016, o projeto é baseado na gravação de duas músicas, em algumas vezes uma inédita e outra cover, produzidas no estúdio da empresa nos Estados Unidos. Ainda não há gravações brasileiras. O objetivo do projeto é ampliar o número de assinantes do serviço que queiram ter acesso a um conteúdo exclusivo do artista. O catálogo do serviço conta com mais de 250 gravações, incluindo cantores do mainstream. A cantora Anitta foi a primeira brasileira a participar do projeto, em janeiro de 2019. O Spotify Singles tem hoje cerca de 1,5 bilhão de streams em suas mais de 525 faixas. O nome singles remete aos discos de vinil promocionais em tamanho compacto que possuíam, em cada lado, uma música ou duas.

Se o Spotify possuir os direitos sobre as gravações do Spotify Sessions e Singles, haverá uma mudança na distribuição dos royalties. De acordo com o site TechCrunch, o serviço tem tentado acordos de gravação tradicionais com artistas. Estes recebem um adiantamento em dinheiro em troca de um percentual das receitas das produções, limitando, assim, a disseminação das músicas em outras plataformas. $\mathrm{O}$ artigo do site também relata que a Apple já oferece uma compensação financeira inicial em troca de exclusividade. O rapper americano Chance The Rapper revelou que recebeu US\$500.000 e ganhou um comercial para divulgar seu álbum Coloring Book; em troca, o novo produto seria exclusivo da Apple Music nas duas primeiras semanas.

Conforme artigo da revista Forbes de 2016, o Spotify tem investido muito em produções próprias. Enquanto serviços como Tidal e Apple Music se concentram em lançar produtos de grandes artistas por um alto preço de forma exclusiva, logo depois distribuindo para outros meios, o Spotify pretende produzir de outra forma: produtos 


\section{midiâtica(e)}

certificados pela empresa que só poderão ser encontrados nela. Isso resulta no aumento da popularidade da plataforma que oferece além de música, podcasts e vídeos.

Fornecer diferenciais é importante nesse novo momento, demarcado pela ascensão de serviços de streaming. Mesmo enfrentando dificuldades, o Spotify tem se destacado por criar produtos dentro da sua plataforma, deixando-a mais dinâmica e atrativa do que os outros serviços. Tanto o projeto Spotify Sessions quanto o Singles apresentam inspirações em moldes já explorados pela indústria da música, em outros suportes como os discos de vinil e também em meios de comunicação como a televisão. Ou seja, são produtos inspirados em fórmulas anteriormente já exploradas.

A busca dessas alternativas cria uma hipótese de exclusão das majors na produção musical, o que diminuiria bastante as despesas dos serviços. Para grandes e antigos artistas que ainda mantém contratos e suas músicas vinculadas às grandes gravadoras, a possibilidade de gravar de forma independente é ainda muito pequena devido aos contratos e carreiras vinculadas com as majors. A atenção está nos artistas de nicho e iniciantes que não têm a obrigação de ter um contrato com gravadoras, que podem criar seu próprio produto e, por meio de uma empresa agregadora, lançar-se nos serviços de streaming. A questão é que, ao investir em artistas iniciantes, o Spotify não tem a mesma receptividade que teria se um artista criado por uma major.

\section{Novos atores: empresas agregadoras}

No meio digital, as transformações na indústria fonográfica proporcionaram o surgimento de novos atores como as empresas agregadoras. Consideradas importantes como um meio de intermediar artistas e serviços de streaming, essas empresas “começaram a surgir no cenário da música digital no fím da década de 1990, com o objetivo de distribuir conteúdo de artistas e selos independentes no universo digital" (FRANCISCO e VALENTE, 2016, p. 353). Hoje, empresas agregadoras como a Agência Milk do Rio de Janeiro e a BRASILMP3 da cidade de Campinas (SP) são o principal meio de intermediação entre artistas que querem hospedar suas músicas em plataformas digitais e os serviços de streaming. As agregadoras funcionam como empresas de tecnologia digital, que se comunicam diretamente com os diversos serviços de música digital na internet. 


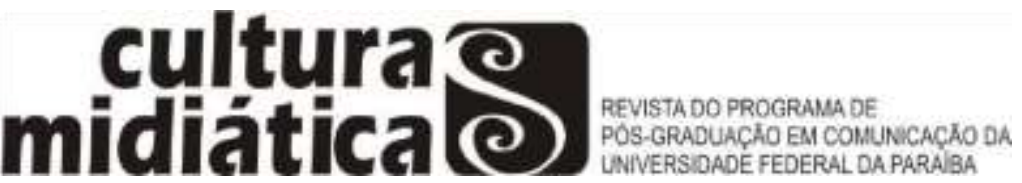

O processo de cadastro do artista até a distribuição de música na internet parece ser semelhante em todas as agregadoras. Giovanni Bonfim, idealizador da BRASILMP3, explica que:

\begin{abstract}
Após fechado o pedido, o primeiro passo é captar todas as informações necessárias para a distribuição. Todas essas informações são recebidas por email e transmitidas ao processo de organização delas em arquivos de metadados, onde são catalogados numa pasta com informações técnicas (ISRC, compositores, intérpretes, sequência das músicas com títulos, gêneros), capa em alta resolução e áudios (wave). Esse arquivo é encaminhado a um servidor na Inglaterra que armazena os dados e envia às Plataformas Digitais no mundo todo. Após 3 meses de publicação, as plataformas digitais nos encaminham relatório com a execução e download de todas as músicas e nós repassamos aos artistas, em página própria na web, para que tenham todo o conhecimento de onde, quando e quais de suas músicas estão sendo executadas, bem como quanto aos royalties são devidos aos compositores (Giovanni Bonfim em entrevista realizada em dezembro de 2017 ao autor).
\end{abstract}

Ao procurar uma agregadora, o artista é quem escolhe como quer fazer sua distribuição de músicas. A empresa BRASILMP3, por exemplo, não cobra anuidade nem mensalidade dos artistas. Há apenas a cobrança de uma taxa única pelo serviço de inclusão do material nas plataformas digitais que varia de acordo com a quantidade de músicas e o tipo de distribuição. Geralmente a validade das músicas distribuídas é de um ano, ficando a renovação à escolha do artista. As agregadoras cuidam do fonograma, e não distribuem valores relativos à composição, ou seja, o direito do autor. O pagamento de royalties devidos em função desse direito é feito diretamente pelas plataformas (FRANCISCO e VALENTE, 2016). O que uma agregadora pode exigir de seus artistas é a exclusividade de distribuição, mas os detentores de direitos sempre serão os artistas. Dessa maneira, a relação entre o Escritório Central de Arrecadação e Distribuição (Ecad) e as agregadoras é praticamente nula. Para um artista independente, como o DJ alagoano Carlos Lins, a arrecadação feita pelo Ecad não é tão simples: "Primeiro que você precisa de uma quantidade considerável de reproduções para ter algum retorno. Segundo que para realmente receber algo, tem que ter uma quantidade mínima de arrecadação" (Carlos Lins em entrevista realizada ao autor em janeiro de 2018). Já sobre o download de músicas gratuito feito pela internet, prática ainda muito comum como forma de consumo, o DJ considera o fato como relativo:

Eu particularmente até disponibilizo diretamente as minhas produções para download, e peço para o público baixar porque para quem é artista independente 


\section{midiâtica(e)}

o foco é que as pessoas consumam o seu material e conheçam o que você faz. Então colocando um "FREE DOWNLOAD" faz com que as pessoas se sintam atraídas a irem conferir. Então, desse ponto de vista não é preocupante. Agora no geral "baixar música sem pagar pela internet" é preocupante sim. No sentido de que a música não é valorizada. É um processo que envolve muita gente: cantores, produtores, compositores, etc. Então é querer consumir um material de graça sem compreender que existe um valor muito grande depositado nele e que tem muito profissional envolvido que merece receber pelo serviço realizado. Muita gente não compreende isso e acha que música, arte e afins não deve ser pago e que deve ser consumido de graça. Acredito que os artistas com maiores públicos sofrem muito com isso porque o investimento em produção e divulgação é muito grande e os downloads ilegais acabam prejudicando o retorno financeiro que o artista deveria ter. Então essa questão é muito relativa de artista para artista porque para um favorece e amplia o trabalho e para outro prejudica muito (Carlos Lins, em entrevista realizada ao autor em janeiro de 2018).

Além da distribuição de música digital, as agregadoras fornecem outros serviços para seus clientes. A Agência Milk do Rio de Janeiro, criada em 2014, se descreve como uma "empresa voltada para desenvolvimento de tecnologias para o mundo da música" que atua de maneira dinâmica no mercado. Os serviços oferecidos pela empresa encontrados no seu site estão divididos em três segmentos: Label Service (serviços relacionados à produção), Desenvolvimento Digital (criação de campanhas estratégicas de divulgação do artista) e Projetos Especiais (serviços de ampliação da marca junto com os artistas).

No mercado de música digital, as empresas agregadoras têm destaque frente às majors por serem empresas que acolhem artistas prontos e diversos oferecendo um serviço diferenciado. Essas empresas também são o principal canal de acesso aos serviços de música na internet, principal tendência de consumo musical atualmente, sem estar relacionada a alguma gravadora. Apesar do vínculo com uma grande gravadora ainda ser o sonho de vários artistas (devido à visibilidade, contatos com a grande mídia e um serviço de marketing de grande abrangência), este não é o único caminho a ser seguido. Normalmente, os artistas iniciam suas carreiras de forma independente ou associados a alguma gravadora local e, ao fazer bastante sucesso, se vincula a uma major. Atualmente, alguns artistas começam também por empresas agregadoras, e depois assinam contrato com alguma gravadora multinacional. É comum também que artistas não criem nenhuma relação com as grandes gravadoras e, ainda assim, consigam benefícios que só seriam possíveis a partir da assinatura de um contrato. 


\section{midiâticale}

A necessidade de artistas procurarem agregadoras também seria descartável. Porém, o que estas empresas digitais oferecem é uma padronização dentro de um sistema, uma forma de artistas de nicho ou independentes conquistarem o mesmo espaço que os cantores lançados pelas majors. Para o DJ Carlos Lins, ter suas músicas hospedadas nos serviços de streaming facilita o acesso do público ao material e dá credibilidade à produção:

\footnotetext{
Saber que o material está numa plataforma mundial de transmissão de música, traz credibilidade. É muito diferente de simplesmente soltar uma faixa para download. Isso enche os olhos do público. Isso nos traz acesso. Essa é a maior vantagem para artistas independentes que usam esse tipo de serviço (Em entrevista ao autor realizada em janeiro de 2018).
}

A diversidade de produções musicais torna-se uma característica das agregadoras que, juntamente das grandes gravadoras, dominam o modo de distribuição de música na internet quando pensamos pela lógica da cadeia produtiva de música. Ainda mantendo uma posição hegemônica, as majors tentam, por um lado, adaptar-se às novas formas de fazer música e, por outro, buscam novos gêneros musicais para investirem, como no caso do sertanejo e da música gospel. Uma pesquisa realizada pela empresa de aferição Crowley Broadcast Analysis do Brasil registrou que, das 30 músicas mais tocadas nas rádios brasileiras em 2017, 28 são do gênero sertanejo.

Por outro lado, as agregadoras também se destacam no processo de distribuição de música como um modelo em desenvolvimento e por apresentarem artistas diversos. Por serem acessíveis e práticas, há uma forte tendência para o crescimento desse modelo de distribuição, principalmente por causa do streaming, considerado o futuro da música. "Porém, mesmo com a estreita relação entre usuários e internet, principalmente por conta dos smartphones, ainda estamos em fase transitória de mídia, pelo menos para o artista independente. Barreira que, em poucos anos, será superada" (Giovanni Bonfim, em entrevista ao autor, em 2017).

A inserção das agregadoras na cadeia produtiva de música parece ainda não afetar definitivamente as grandes gravadoras, mas representa uma transição. Por fazerem parte de um novo momento da indústria da música impulsionado pela internet, esses novos atores promovem uma reorganização da música digital anteriormente produzida e encontrada sem nenhuma padronização. Os serviços de streaming tornam-se elementos 


\section{midiâticale}

centrais na cadeia produtiva da música, por receberem músicas das majors e das agregadoras, resultando numa relação entre novos e velhos atores vista de forma não ameaçadora, mas em transformação.

\section{Considerações Finais}

É inegável que, por um lado, o streaming vem transformando o mercado de música, proporcionando novas formas de artistas de nicho se incluírem nas plataformas digitais. Por outro, está desestruturando a indústria fonográfica. O processo de digitalização iniciou uma revolução que, com a internet, transformou a indústria fonográfica, ampliando a visibilidade de artistas independentes e as formas de produção, distribuição e consumo de música. Os projetos do Spotify e as empresas agregadoras são dois exemplos de alternativas musicais criadas a partir de suportes digitais pela internet e que não precisam ter contato com as majors, implicando num reposicionamento destas.

As majors têm buscado formas de se manterem atuantes e rentáveis. A influência dessas empresas na mídia ainda é importante, assim como a facilidade de contato com empresas internacionais. É importante lembrar que os serviços de streaming mantêm vínculo com as grandes gravadoras porque precisam da autorização delas para ter as músicas do mainstream em suas plataformas. Assim, a ideia de uma exclusão das majors dos processos de produção parece utópica ou lenta, considerando-se que essas gravadoras podem entrar em acordos ou até mesmo comprar empresas agregadoras, como fizeram com diversos selos musicais, garantindo também artistas independentes.

O streaming é a tendência para o consumo digital de diferentes produtos. A música foi pioneira nesse aspecto e hoje é comum assistirmos a shows e produtos audiovisuais, programações televisivas ou então jogar vídeo game de forma totalmente online e nas opções paga ou gratuita com publicidade. Todos esses exemplos evidenciam a internet voltada para o mercado, utilizando-se de técnicas da Indústria Cultural reformuladas para o meio digital e buscando formas de conseguir audiência em um novo ambiente. A música pode ser considerada um dos produtos mais populares nesse processo, devido ao seu desenvolvimento no meio digital nos últimos anos. A reconfiguração da indústria fonográfica no ambiente digital, com a inserção de empresas que utilizam a música como principal insumo, com os acordos e parcerias de empresas diversas, e a cobrança de 


\section{midiâticale}

impostos e direitos autorais nas plataformas digitais, evidenciam interesses de diversos setores que percebem a música como um importante produto cultural.

\section{Referências}

CRUZ, Leonardo Ribeiro da. Os novos modelos de negócio da música digital e a economia da atenção. Revista Crítica de Ciências Sociais, n. 109, p. 203-228, 2016.

DE MARCHI, Leonardo. Diversidade cultural nos mercados de comunicação e cultura: um panorama das discussões e métodos de pesquisa na indústria fonográfica. Teoria e Cultura, v. 13, n. 2, 2018.

FRANCISCO, Pedro Augusto P.; VALENTE, Mariana Giorgetti. Da rádio ao streaming: ECAD, direito autoral e música no Brasil. Beco do Azougue, 2016.

KISCHINHEVSKY, Marcelo. Rádio e mídias sociais: mediações e interações radiofônicas em plataformas digitais de comunicação. Mauad Editora Ltda, 2016.

KISCHINHEVSKY, Marcelo; VICENTE, Eduardo; DE MARCHI, Leonardo. Música infinita: serviços de streaming como espaços híbridos de comunicação e consumo musical. Anais, 2015.

SANTOS, Verlane. A firma-rede e as novas configurações do trabalho nas telecomunicações brasileiras. Coleção Eptic, n. 5 - Aracaju: Editora UFS, 2008.

VICENTE, Eduardo. Indústria da música ou indústria do disco: a questão dos suportes e de sua desmaterialização no meio musical. Rumores, v. 6, n. 12, 2012.

VICENTE, Eduardo; KISCHINHEVSKY, Marcelo; MARCHI, Leonardo de. A consolidação dos serviços de streaming: reconfiguração dos mercados de mídia sonora e desafios à diversidade musical no Brasil. Anais, 2016. 